\title{
Oficinas de boas práticas de fabricação: construindo estratégias para garantir a segurança alimentar
}

\author{
Workshops for good manufacturing practices: \\ building strategies for ensuring food security
}

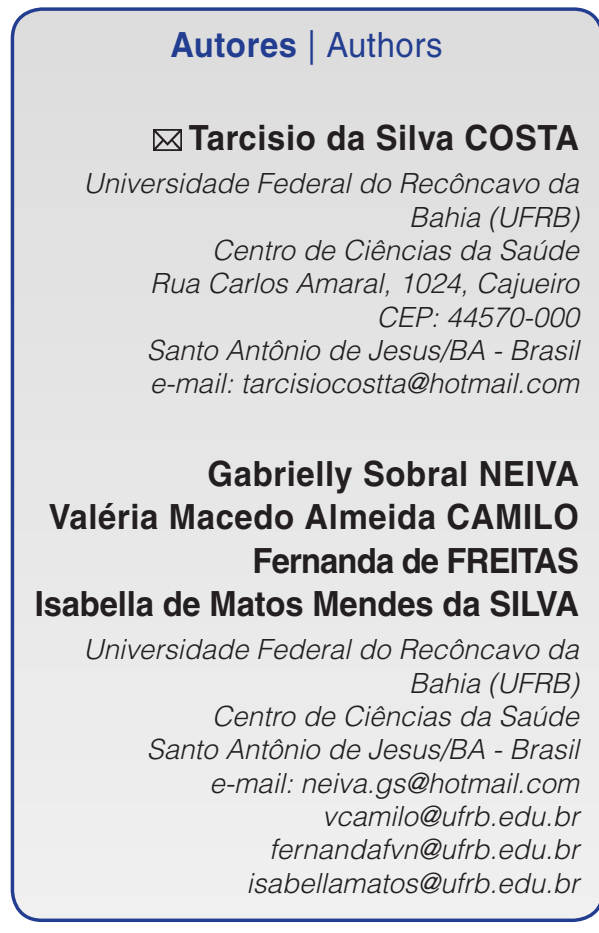

Autor Correspondente / Corresponding Author Publicado / Published: dezembro/2012

\section{Resumo}

A comercialização de alimentos tradicionais resgata a história e a cultura presentes nos alimentos. Os pescadores artesanais são os principais responsáveis pelo abastecimento do mercado nacional. Considerando-se a importância da adoção de procedimentos de Boas Práticas de Fabricação em toda cadeia produtiva, o presente trabalho visa a socializar uma experiência construtiva de uma oficina de Boas Práticas de Fabricação para pescadoras. Diante disso, realizou-se um levantamento de conceitos e atitudes voltadas para produção segura de alimentos, utilizando-se como instrumento entrevistas, além da observação de seus hábitos e atitudes. Os resultados evidenciam que estas pescadoras percebem as Boas Práticas de Fabricação como sinônimo de higiene e de poder comercializar o pescado sem reclamações; porém, as mesmas não têm noção dos procedimentos de Boas Práticas de Fabricação na sua atividade. O processo formativo se constitui como uma das estratégias de base para consolidação dos grupos, sendo as oficinas alternativas eficientes, de fácil execução e baixo custo.

Palavras-chave: Oficinas de formação; Boas práticas de fabricação; Pescadoras.

\section{Summary}

The marketing of traditional foods recalls the history and culture in feeding. The fishermen are primarily responsible for supplying the domestic market. Considering the importance of adopting procedures for Good Manufacturing Practices throughout the production chain, this paper aims to socialize a constructive experience of a Good Manufacturing Practices workshop for fishers. Therefore, we carried out a survey of concepts and attitudes towards safe food production, using interviews as an instrument, and are observed their habits and attitudes. The results show that these Good Manufacturing Practices perceive as synonymous with health and able to market the fish without complaint, but they are not aware of the procedures for Good Manufacturing Practices activities. The training process is constituted as one of the basic strategies for strengthening these groups, workshops efficient alternatives, easy implementation and low cost.

Key words: Training workshops; Good manufacturing practices; Fisherwomen. 


\section{Introdução}

A comercialização de alimentos tradicionais, além de agregar maior valor aos produtos rurais, tem como finalidade resgatar a história e a cultura presentes nesses alimentos (ZUIN e ZUIN, 2008). Segundo Ott (1944 apud SOUTO e MARTINS, 2009), a região do Recôncavo Baiano constitui-se em um dos berços da cultura baiana, sendo a pesca artesanal uma de suas principais manifestações. Além de desempenharem funções ecológicas importantes, os manguezais representam, para muitas populações tradicionais, uma das poucas alternativas de subsistência e renda. Os recursos provenientes do ambiente são fundamentais para a sobrevivência de muitas comunidades pesqueiras (NISHIDA, 2000; MARTINS e SOUTO, 2006).

Um estudo da Escola Superior de Propaganda e Marketing, Aquicultura e Pesca (ESPM, 2008), afirma que os pescadores artesanais são os principais responsáveis pelo abastecimento do mercado nacional, embora a maior parte dessa produção passe pelos grandes atacadistas, frigoríficos e indústrias, que fazem o processamento, a industrialização e a revenda para varejistas, restaurantes, bares e mercados locais. Salienta-se que os pescadores se utilizam de práticas tradicionais de pesca, a comercialização do pescado se dá por meio de um ou mais intermediários e existe uma desorganização ao longo de toda a cadeia produtiva, com más condições de manipulação, armazenamento e transporte; tais condições, decisivamente, contribuem para a perda da qualidade sanitária e a deterioração do pescado fresco, que geralmente está disponível ao consumidor nas feiras livres, mercados e peixarias. Atualmente, a prevenção e a eliminação, ou ainda a redução destes aspectos negativos a níveis adequados, ficam sob a responsabilidade do produtor (SANTOS, 2006).

A qualidade higiênico-sanitária é um fator de segurança alimentar que tem sido amplamente discutida, uma vez que as doenças transmitidas por alimentos contaminados têm aumentado consideravelmente; tal incremento ocorre, possivelmente, como consequência do reaquecimento e da refrigeração inadequados, da preparação de alimentos com muita antecedência (AKUTSU et al., 2005) ou da falta de conhecimento e/ou negligência dos manipuladores de alimentos quanto às Boas Práticas de Fabricação (STEFANELLO et al., 2009).

As Boas Práticas de Fabricação (BPF), conhecidas internacionalmente como Good Manufactures Pratices (GMP), são um conjunto de princípios, regras e procedimentos que regem o correto manuseio dos alimentos, abrangendo desde a matéria-prima até o produto final. São normas de procedimentos para atingir um determinado padrão de identidade e qualidade de um produto e/ou serviço na área de alimentos, cuja eficácia e efetividade devem ser avaliadas por meio de inspeção e/ou investigação (SILVA JÚNIOR, 2007).

Considerando-se a importância da adoção de procedimentos de Boas Práticas de Fabricação (BPF) em toda cadeia produtiva do pescado, a fim de garantir a qualidade higiênico-sanitária e o fortalecimento da associação de pescadoras no mercado, o presente trabalho visa a socializar uma experiência de construção de uma oficina de BPF para pescadoras no Recôncavo Baiano.

\section{Material e métodos}

A pesquisa é de cunho qualitativo, em função da necessidade de se realizar um estudo exploratório acerca da percepção das pescadoras sobre as BPF. Envolveu uma associação de pescadoras de um município do Recôncavo da Bahia, pertencente ao programa de fortalecimento de empreendimentos de economia solidária e da agricultura familiar, no contexto da segurança alimentar no território do Recôncavo Baiano. As ações foram articuladas no ambiente territorial e acadêmico, com a integração entre a associação de pescadoras e o envolvimento direto da Incubadora de Empreendimentos Solidários - INCUBA/UFRB e dos Projetos Territoriais Estratégicos.

A metodologia planejada para o desenvolvimento dos trabalhos baseou-se nos princípios de promoção da autogestão, fortalecendo a formação de sujeitos no processo de decisão: a) construção dos conhecimentos a partir da valorização e do resgate da experiência de vida e de trabalho, por meio do respeito e do reconhecimento da cultura, do saber e dos anseios do empreendimento solidário; b) realização de exercícios práticos cotidianos e de linguagem acessível que contribuam para a compreensão, a participação e a assimilação dos conteúdos; c) busca de um processo contínuo de educação e trabalho, voltado para a segurança alimentar e o desenvolvimento territorial. A Figura 1 mostra as etapas de construção das oficinas.

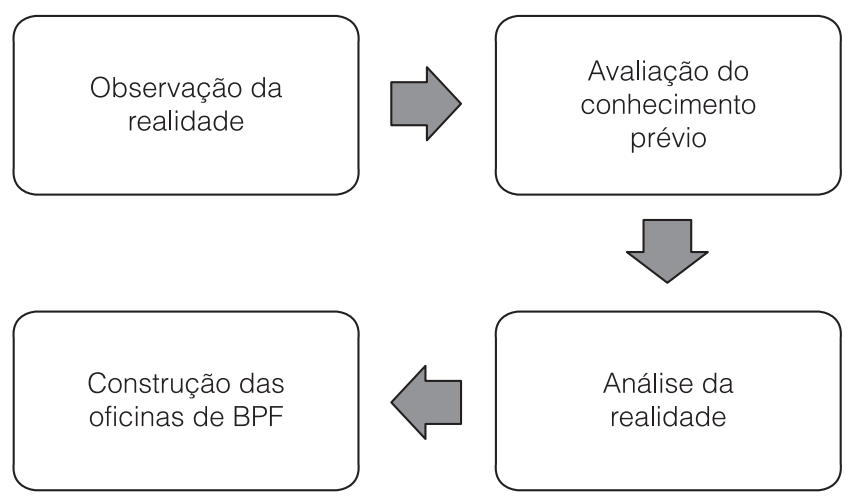

Figura 1. Etapas de execução metodológica. 
Inicialmente, observou-se o trabalho das pescadoras, com registro fotográfico de hábitos e atitudes durante o desenvolvimento das atividades, e um processo de escuta dos relatos espontâneos das experiências. Segundo Freire (2000), se, na verdade, o sonho que nos anima é democrático e solidário, não é falando aos outros, de cima para baixo, sobretudo, como se fôssemos os portadores da verdade a ser transmitida aos demais, que aprendemos a escutar, mas é escutando que aprendemos a falar com eles. Somente quem escuta paciente e criticamente o outro, fala com ele, mesmo que, em certas condições, precise falar a ele. Falar impositivamente é o que jamais faz quem aprende a escutar para poder falar com ele.

Em um segundo momento, foi realizado um levantamento de conceitos e atitudes voltados para produção segura de alimentos, utilizando-se como instrumento a entrevista, realizada pelos estudantes previamente capacitados, na qual se abordaram seis questões referentes aos seguintes aspectos: idade, escolaridade, características socioeconômicas e sobre o conceito de BPF. Após a aplicação da entrevista, ocorreu uma sensibilização inicial, pela qual as pescadoras foram instigadas a responder sobre a importância das BPF para o seu trabalho e a influência do produto de seu trabalho para a saúde dos clientes.

Considerando-se o registro fotográfico, a análise do processo de escuta e as entrevistas, foi realizada uma associação da prática com o discurso e, a partir desta análise, foram construídos os temas das oficinas de formação em BPF. A formação foi distribuída em módulos com conceitos básicos de BPF: higiene pessoal e de alimentos; ambiente; utensílios e equipamentos; doenças de transmissão hídrica e alimentar, e processamento de alimentos.

Para o momento de confecção e exercício das atividades extensionistas, foram consideradas que as práticas e percepções de higiene são constituídas pelas experiências dos sujeitos, e que o desenvolvimento das ações educativas é mais efetivo quando se levam em conta os modos de interpretação das recomendações da Vigilância Sanitária e a construção sociocultural de saberes e práticas locais. Partiu-se do pressuposto de que as noções de higiene e limpeza são culturalizadas, construídas e partilhadas por sujeitos sociais que atribuem significados às suas práticas cotidianas.

As oficinas de BPF foram desenvolvidas a partir dos resultados encontrados. Os aspectos éticos foram respeitados, conforme Parecer 196/96, que regulamenta normas de pesquisas envolvendo seres humanos, sendo solicitada autorização para a realização do trabalho.

\section{Resultados e discussão}

A Associação é constituída por cerca de 120 pescadoras da comunidade, sendo que as pescadoras participantes deste estudo tinham idade entre 30 e 45 anos, e, em sua maioria (80,3\%), relataram saber ler e escrever. Cerca de $80 \%$ dessas mulheres convivem com a pesca diária desde a infância e 66,7\% das entrevistadas têm, nesta atividade, sua única fonte de renda.

A Tabela 1 demonstra os dados socioeconômicos das pescadoras participantes do estudo.

Com uma jornada longa a cumprir, as pescadoras se orientam de acordo com a maré. Utilizando embarcações ou até mesmo a pé, elas vão à praia para a coleta dos mariscos. Os principais mariscos coletados são: o bebe-fumo (Anomalocardia brasiliana), o machadinha (Brachidontes exustus), o sururu (Mytella sp.) e as ostras (Crassostrea rhizophorae). Comumente, utilizam baldes e outros recipientes para armazená-los. O seu processamento é realizado artesanalmente nas casas das associadas.

A maior parte da comercialização é realizada de forma conjunta na sede da associação, onde, no futuro, haverá uma unidade de beneficiamento para as associadas, e de onde será repassado o pescado para os consumidores, supermercados ou peixarias da região. A outra parte é realizada de forma individual em suas próprias casas, local em que o pescado é vendido diretamente aos clientes ou para intermediários, o que provoca perdas de qualidade do produto e perdas financeiras, já que o pescado é revendido pelos atravessadores por preços muito superiores àqueles valores que pagaram às pescadoras. Souza e Mello (1999) destacam que o atravessador é um agente de retenção dos lucros, diminuindo os ganhos dos pescadores.

Uma informação preocupante relatada é que todas as pescadoras nunca receberam treinamento sobre as BPF, uma vez que por Ferreira et al. (2001 apud ARAÚJO et al., 2010) e Stefanello et al. (2009) ressaltam que os manipuladores de alimentos devem receber treinamento continuamente quanto aos processos de produção, transporte, armazenamento e distribuição dos alimentos. Tavolaro et al. (2006) destacam que, para haver modificações nos hábitos higiênicos desses manipuladores, as crenças e atitudes relacionadas à segurança alimentar devem ser estudadas, para que sejam previstas as melhores formas de intervenção.

Tabela 1. Dados socioeconômicos das pescadoras de um município do Recôncavo da Bahia, 2011.

\begin{tabular}{ll}
\multicolumn{1}{c}{ Questões } & \multicolumn{1}{c}{ Resultados } \\
Faixa etária & Entre 30 e 45 anos \\
Escolaridade & $\begin{array}{l}80,3 \% \text { relatam saber ler e } \\
\text { escrever }\end{array}$ \\
Tempo de trabalho com o & $80 \%$ relatam trabalhar desde \\
pescado & a infância \\
Renda & Única fonte de renda para \\
& $66,7 \%$ das entrevistadas \\
\hline
\end{tabular}


Quando questionadas se o produto de trabalho pode influenciar na saúde dos clientes, 60,7\% responderam positivamente, associando episódios de diarreia e/ou vômitos apresentados após o consumo do pescado com o manuseio do alimento. O relato de uma das entrevistadas sobre o conceito de BPF reafirma tal compreensão: "[...] são como você consegue ter os mariscos pra não ter bactérias [...]". Ainda sobre o conceito de BPF, as entrevistadas, em sua maioria, associaram a esse conceito a relação de "limpeza", "asseio" e "ter higiene" no tratamento do pescado.

Quanto à questão da importância das BPF à saúde, em um dos seus relatos, uma das entrevistadas afirma: "é pra saúde da gente, pra não pegar bactéria, para poder vender e não receber reclamação".

Os resultados obtidos evidenciam que as pescadoras percebem as BPF como sinônimo de higiene e de poder comercializar o pescado sem reclamações por parte dos clientes; porém, as mesmas não têm noção dos procedimentos de BPF na sua atividade, o que mostra a necessidade de formação. Segundo Maluf e Menezes (2001), ao se apoiar pequenos empreendimentos rurais e urbanos dedicados ao cultivo, à transformação e à comercialização de produtos agroalimentares, amplia-se, ao mesmo tempo, a disponibilidade de alimentos de qualidade de um modo menos custoso, valorizando a diversidade nos hábitos de cultivo e de consumo.

Com base nos conceitos explicitados e nas vivências, os módulos das oficinas foram construídos numa relação bilateral, integrando conhecimentos e experiências acumulados na academia (pelos pesquisadores) com o saber popular (pescadoras) dos ambientes pesquisados. Durante as intervenções, as pescadoras foram estimuladas a citar suas contribuições ao módulo estudado e, a partir de uma abordagem, foram sendo construídas novas noções sobre a temática. Tais práticas apresentam um significado público que podem ser interpretadas à luz de uma determinada dinâmica cultural.

Ao final das oficinas, as pescadoras foram novamente instigadas a relatar a experiência vivida e explicitar sobre o processo produtivo de pescado e as BPF. As mesmas expuseram perceber uma melhoria nas condições de trabalho, um melhor entendimento das BPF e um apoio para consolidação dos grupos.

\section{Conclusões}

O processo formativo se constitui como uma das estratégias e uma base para a consolidação dos grupos como uma forma de fortalecimento das práticas organizacionais com a preocupação na temática de segurança alimentar.
As oficinas de BPF são uma das alternativas eficientes e criativas, de fácil execução e baixo custo, que podem ser aplicadas nos empreendimentos para que estes tenham condições de atender às exigências da inspeção sanitária e de boas práticas de fabricação de alimentos, em conformidade com a Segurança Alimentar e Nutricional. Além disso, é importante o debate com os trabalhadores dos empreendimentos para a formação nesta temática, na busca de compreender o modelo de produção de alimentos, a disponibilidade de alimentos, a renda e as suas condições de vida.

Este estudo comprovou ser viável a reaplicação dessa metodologia em outras comunidades com situação semelhante.

\section{Referências}

AKUTSU, R. C.; BOTELHO, R. A.; CAMARGO, E. B.; SÁVIO, K. L. O.; ARAÚJO, W. C. Adequação das boas práticas de fabricação em serviços de alimentação. Revista de Nutrição, Campinas, v. 18, n. 3, p. 419-427, maio/jun. 2005. http://dx.doi.org/10.1590/ S1415-52732005000300013

ARAÚJO, W. D. B.; ALMEIDA, M. E. F.; SANTOS, C. E. M.; PIZZIOLO, V. R. Avaliação do conhecimento de manipuladores de alimentos quanto às boas práticas de fabricação. Vivências, Erechim, v. 6, n. 9, p. 67-73, 2010. Disponível em: http:// www.reitoria.uri.br/ vivencias/Numero_009/artigos/artigos_ vivencias_09/n9_8.htm. Acesso em: 21 ago. 2011.

ESCOLA SUPERIOR DE PROPAGANDA E MARKETING AQUICULTURA E PESCA - ESPM. Camarões - Estudos de Mercado. Sebrae, Escola Superior de Propaganda e Marketing, 2008. Disponível em: http://201.2.114.147/bds/ BDS.nsf/47ACFD29DAFB1D2D832574DC00461D54/\$File/ NT0003906A.pdf. Acesso em: 23 ago. 2011.

FREIRE, P. Pedagogia da Autonomia. 15. ed. Rio de Janeiro: Paz e Terra, 2000.

MALUF, R. S.; MENEZES, F. Caderno "Segurança Alimentar". In: FÓRUM SOCIAL MUNDIAL, 1., Porto Alegre, 2001. Anais.... Porto Alegre: FSM, 2001. Disponível em: http://ag20.cnptia. embrapa.br/Repositorio/seguranca+alimentar_000gvx|xe0q02w x7ha0g934vgwlj72d2.pdf. Acessado em 30 de Janeiro de 2012.

MARTINS, V. S.; SOUTO, F. J. B. Uma análise biométrica de bivalves coletados por marisqueiras no manguezal de Acupe, Santo Amaro, Bahia: Uma abordagem etnoconservacionista. SITIENTIBUS Série Ciências Biológicas, Feira De Santana, v. 6, p. 98-105, 2006. Número Especial - Etnobiologia.

NISHIDA, A. K. Catadores de Moluscos do Litoral Paraibano: Estratégias de Subsistência e Formas de Percepção da Natureza. 2000. 144 f. Tese (Doutorado em Ecologia e Recursos Naturais)-Universidade Federal de São Carlos, São Carlos, 2000.

SANTOS, C. A. M. L. A qualidade do pescado e a segurança dos alimentos. In: SIMPÓSIO DE CONTROLE DO PESCADO, 2., 
São Paulo, 2006. Anais.... São Paulo: Instituto de Pesca, 2006. Disponível em: <ftp://ftp.sp.gov.br/ftppesca/qualidade_ pescado.pdf>. Acesso em: 21 ago. 2011.

SILVA JÚNIOR, E. A. Manual de Controle Higiênico-sanitário em Alimentos. 6. ed. São Paulo: Varela, 2007.

SOUTO, F. J. B.; MARTINS, V. S. Conhecimentos etnoecológicos na mariscagem de moluscos bivalves no Manguezal do Distrito de Acupe, Santo Amaro - BA. Biotemas, Florianopolis, v. 22, n. 4, p. 207-218, dez. 2009

SOUZA, R. M.; MELLO, R. L. S. Aspectos sócio-econômicos das marisqueiras de Crassostrea rhizophorae (Guilding, 1828) do Município de Itapissuma - PE. In: ENCONTRO BRASILEIRO DE MALACOLOGIA, 16., 1999, Recife. Anais... Recife: Sociedade Brasileira de Malacologia, 1999. p. 158. Resumo.
STEFANELLO, C. L.; LINN, D. S.; MESQUITA, M. O. Percepção sobre Boas Práticaspor cozinheiras e auxiliares de cozinha de uma UAN do noroeste do RioGrande do Sul. Vivências, Erechim, v. 5, n. 8, p. 93-98, 2009.

TAVOLARO, P.; OLIVEIRA, C. A. F.; LEFEVRE, F. Avaliação do conhecimento em práticas de higiene: uma abordagem qualitativa. Interface: Comunicação, Saúde, Educação, Botucatu, v. 10, n. 19, p. 243-254, 2006. http://dx.doi. org/10.1590/S1414-32832006000100017

ZUIN, F. S.; ZUIN, P. B. Produção de alimentos tradicionais contribuindo para o desenvolvimento local/regional e dos pequenos produtores rurais. Revista Brasileira de Gestão e Desenvolvimento Regional, Taubaté, SP, v. 4, n. 1, p. 109-127, 2008. 